\title{
Lean 4.0: A New Holistic Approach for the Integration of Lean Manufacturing Tools and Digital Technologies
}

\author{
Luana Sposito Valamede \\ Science and Technology Center, \\ Mackenzie Presbyterian University, Campinas, Brazil. \\ E-mail: luana_valamede@goodyear.com \\ Alessandra Cristina Santos Akkari \\ Science and Technology Center, \\ Mackenzie Presbyterian University, Campinas, Brazil. \\ Corresponding author: alessandra.akkari@mackenzie.br
}

(Received April 28, 2020; Accepted May 25, 2020)

\begin{abstract}
Due to the highly dynamic and competitive environment, organizations are led to rethink their processes and strategies. In the industrial field, Lean Manufacturing $(\mathrm{LM})$ is widely recognized as a traditional approach to eliminate waste in the value stream and ensure the efficiency of production processes. On the other hand, Industry 4.0 has recently emerged, incurring disruptive changes in manufacturing processes based on a technology-driven approach. The integration of these two philosophies to achieve organizational goals is interesting in order to guarantee competitiveness, especially for manufacturing companies. This paper proposed an integration of LM tools and technologies 4.0, considering the perspectives of the industrial field in the digital era. Based on a three-step methodology, which included technological and industrial mapping, it was identified 25 synergy points. From interactions of LM tools mainly with Big Data Analytics, The Cloud, Virtual Simulation and Augmented Reality, multi-level circular diagrams pointed out the main contributions of Just in Time 4.0 (JIT 4.0), Kaizen 4.0, Kanban 4.0, Poka-Yoke 4.0, Value Stream Mapping 4.0 (VSM 4.0) and Total Productive Maintenance 4.0 (TPM 4.0). Also, five attributes of Lean 4.0 were identified, highlighting the integration between processes, devices and stakeholders; waste minimization; and autonomous, pointing to gains for the organization from this holistic integration approach.
\end{abstract}

Keywords- Lean manufacturing, Industry 4.0, Lean 4.0, Digital technologies, Value chain.

\section{Introduction}

Companies around the world have been experiencing challenges as a result of economic crises, directing the search for new business opportunities and strategies to obtain profit and gain market share. Furthermore, the environment in which organizations are inserted is highly dynamic, forcing them to constantly adapt to new practices and market needs in order to maintain the sustainability of its processes (Chang and Cheng, 2019).

Specially for manufacturing companies, operational processes must be increasingly focused on quality, productivity and low costs, in an attempt to ensure their competitiveness. Associated with this fact, the growing demands of the consumer stand out, which in a digital era require quick and effective responses from organizations in face of their expectations (Pagliosa et al., 2019).

In fact, in the Fourth Industrial Revolution, due to the complexity in the manufacturing system, the top priorities of process management are to accelerate production, improve quality and reduce costs (Alkan et al., 2018). To achieve these goals, technologies 4.0 are emerging as advanced strategies 
to drive improved process efficiencies while reducing operating costs and maintaining global quality standards (Rüßmann et al., 2015; Schmidt et al., 2015). However, it is noteworthy that Industry 4.0 has often been presented as the solution that will, by itself, ensure the productive sector success in the digital era, leaving a gap on the efforts to improve the organizational processes used until then, such as those associated with Lean Manufacturing (LM) (Alkan et al., 2018; Dombrowski et al., 2017; Wagner et al., 2017).

LM is considered a management philosophy developed in the beginning of the Third Industrial Revolution and has been implemented and adapted in different sectors of industries, incurring in increasing the organization's efficiency (Tayaksi et al., 2020). Due to fixed manufacturing sequences and slow responsiveness, associated with increasing pressures from customer expectations regarding product variability, LM may not meet the new needs imposed by the digital technology applied in industrial field, and its suitability for future value chains can be limited (Ma et al., 2017; Mayr et al., 2018). From this perspective, the question arises whether the principles disseminated by LM can be applied in harmony with advanced manufacturing.

In this context, it is highlighting the LM difficulties of make industrial processes more flexible when they are faced with product mix, rapid demand variations or low volume production. These situations are linked to the production personification according to requirements of each consumer, considering one of the points defended in the industry-customer relationship in the digital age. The new manufacturing context may require the introduction of new machines and a new production flow balance, as well as the need for stock to stabilize an interrupted flow (Alkan et al., 2018; Čiarnienè and Vienažindienè, 2012).

Since these two approaches are fundamentally different, as Industry 4.0 has begun to move forward in production with autonomous and flexible systems based on a technology-driven approach, while LM keeps traditional processes focused on efficiency, this paper proposes a holistic integration of LM tools and technologies 4.0, considering the perspectives of the industrial environment in the digital era. The design of a holistic integration offers a way to companies to identify the importance and the relationships between LM and Industry 4.0, pointing out the convergences and the organizational gains from the interaction between the Just in Time (JIT), Kanban, Poka-Yoke, Value Stream Mapping (VSM), Kaizen and Toyota Productive Maintenance (TPM) with digital technologies. This integration proposal means the alignment of a lean production system according to the technological trends arising from Industry 4.0, demonstrating that the organizational goals can be achieved jointly by these two approaches. Therefore, this study contributes to the industrial field through the exploration of two philosophies that, when applied together, can optimize company indicators, pointing out a practical path to be followed by lean companies from different sectors that are looking to adapt to the Fourth Industrial Revolution.

\section{Literature Review}

\subsection{Lean Manufacturing}

The concept of Lean Manufacturing (LM) was originated at Toyota Motor Corporation, a Japanese automotive manufacturer. To ensure the company's development and survival, Taiichi Ohno, Toyota's chief engineer, introduced the Toyota Production System (TPS) in 1988, a business strategy focused on working with the limited resources available in Japan (Behrouzi and Wong, 2011). In contrast to the U.S. manufacturing model, which is operated with many different machines and had a large amount of intermediate products, the LM is focused on elimination of any type of waste, 
aiming to supply the exact quantity of products required by customers, in the right time and with the high quality (Tayaksi et al., 2020).

Womack et al. (1990) define the LM production logic as a dynamic process based on principles and practices, which are aimed to achieve the continuous improvement through elimination of waste. Being applicable across variables business domains, LM provides multidisciplinary management practices which integrates quality processes, work teams, and customer and supplier networks (Mrugalska and Wyrwicka, 2017; Womack et al., 1990).

For LM implementation in the organizational context, it is necessary to use the LM tools, as well as the joint action and motivation of all employees of the company. In this article, there will be detailed the LM tools JIT, Kanban, Poka-Yoke, VSM, Kaizen and TPM, as descripted according to Table 1 .

Table 1. The main LM tools applied in the productive context

\begin{tabular}{|l|l|}
\hline LM TOOL & \multicolumn{1}{c|}{ DESCRIPTION } \\
\hline JIT & $\begin{array}{l}\text { Being on of TPS pillars, JIT aims to produce only the essentials at the time, date and quantity required. Unlike } \\
\text { traditional processes, it pulls production along the supply chain, processing materials only if the next operation re- } \\
\text { quires them. From the perspective of system-wide dependency, JIT enables advantages in order to reduce problems } \\
\text { with overproduction, transport, lead time, excessive resource movement and product defect (Mayr et al., 2018; } \\
\text { Sanders et al., 2016). }\end{array}$ \\
\hline Kanban & $\begin{array}{l}\text { Kanban system can reach a minimum stock at any time. This tool makes the processes and materials flow through } \\
\text { the cards which represent a sequence of orders and resources on the shop floor, while record the main information of } \\
\text { the efficient production flow (Kolberg and Zühlke, 2015). }\end{array}$ \\
\hline Poka-Yoke & $\begin{array}{l}\text { Devices that prevent and detect losses from any source, being able to automatically cease the production line when } \\
\text { needed. They stand out for their simplicity of operation and their intuitive design features. These devices help to } \\
\text { reduce variability and maintain stability and control of production processes (Mrugalska and Wyrwicka, 2017; Zhang, } \\
\text { 2014). }\end{array}$ \\
\hline VSM & $\begin{array}{l}\text { The value stream consists of all actions currently required in the production line, covering the value added as well as } \\
\text { the non-aggregating ones. The visual representation of this flow enables a systematic process analyze which perme- } \\
\text { ates various levels of a production structure. This analyze is used in order to eliminate waste, streamline work tasks, } \\
\text { reduce lead time and costs, and increase productivity quality (Wagner et al., 2017). }\end{array}$ \\
\hline Kaizen & $\begin{array}{l}\text { Kaizen philosophy promotes improvements as a result of continuous effort and the kaizen events are often associated } \\
\text { with waste reduction techniques, lead time and workstation balancing (Knechtges and Decker, 2014). }\end{array}$ \\
\hline TPM & $\begin{array}{l}\text { This concept aims to improve productivity and quality, as well as motivating employees and contributing to job } \\
\text { satisfaction. It has an innovative maintenance approach that optimizes equipment effectiveness, eliminates failures } \\
\text { and promotes unattended operator maintenance through daily activities which involves the workforce (Mayr et al., } \\
\text { 2018; Singh et al., 2013). }\end{array}$ \\
\hline
\end{tabular}

\subsection{Industry 4.0}

Industrial revolutions are historically associated with disruption in production models. It began with the emergence of steam engines, advancing to the use of electricity and culminating in the Digital Revolution, which introduced the application of computer innovations in manufacturing context. The rapid pace of technological development is changing how the society works and relates to the environment (Eliasen et al., 2018).

Nowadays, the Fourth Industrial Revolution aims to achieve faster innovation in manufacturing processes with greater value chain efficiency (Ben-Daya et al., 2019). Focusing on processes flow automation, Industry 4.0 enables flexibility and customization of products and services and, consequently, it increases the profitability maximization (Schmidt et al., 2015). 
International Journal of Mathematical, Engineering and Management Sciences

Vol. 5, No. 5, 851-868, 2020

https://doi.org/10.33889/IJMEMS.2020.5.5.066

Industry 4.0 could be considered a new production stand, once it aims to develop a smart and open manufacturing platform for the data application an industrial network. Converting common machines into self-conscious and self-learning equipment to improve their overall performance and management, smart factories will be able to monitor real-time data, track product status and positions, and maintain instructions for controlling the production processes (Javaid and Haleem, 2019; Vaidya et al., 2018).

The digital revolution will impact in a complex way on production systems, providing solutions through the technologies 4.0 combinations. These associations lead organizations to rethink the value chain of their new products and how to develop them to insert on market. In this article, the most cited technologies 4.0 in the literature were studied, including Big Data Analytics, Automated Guided Vehicles (AGVs), Virtual Simulation (VS), Cybersecurity, Cloud Computing (The Cloud), Additive Manufacturing (AM) and Augmented Reality (AR) (Kolberg and Zühlke, 2015; Mayr et al., 2018; Pereira et al., 2019; Sanders et al., 2016).

Big Data Analytics refers to a large amount of varied data, which is processed into information with high capture speed and greater visibility, improving the efficiency and effective-ness of organizations in decision making processes (Vaidya et al., 2018).

In Industry 4.0 context, robots that are autonomous, flexible, cooperative and with many skills conceptualize AGVs. They are able to operate in the real world without any external control for long periods of time. Also, without the need to isolate their work area, and human can work together which makes processes more productive and economical (Mayr et al., 2018).

VS is a computational system-based modeling which fosters real-time data to mirror the physical world into a virtual model that includes machines, products, and humans. This simulation provides a prior analysis of all the steps that make up the process, presenting performance estimates for production indicators (Bahrin et al., 2016).

Cybersecurity technology aims to protect programs, computers, networks and data, ensuring security the security and reliability of communications and the management of resources and information. Smart factories will work with standard communication protocols and high connectivity among all links of value chain (Rüßmann et al., 2015; Ustundag and Cevikcan, 2018).

The Cloud provides unified communication between the technology level (smart products and cyber-physical systems) and the highest hierarchy level in an organization. Innovation that increases data sharing across enterprise boundaries, improves system performance, makes it more agile and flexible, and reduces costs (Ma et al., 2017; Vaidya et al., 2018).

AM refers to a set of computer-automated processes that construct products layer by layer, based on three-dimensional models designed in Computer-Aided Design software. This approach permits for an object being produced in one step or with a reduction in the number of steps, as well as provides easily customized products (Bahrin et al., 2016).

Finally, AR technology works with overlapping virtual objects with the existing environment. In AR displays, virtual and real information, previously acquired with a camera, are digitally merged and represented on a screen, creating an interface between employees and digital products or equipment (Mayr et al., 2018; Rüßmann et al., 2015). 
International Journal of Mathematical, Engineering and Management Sciences

Vol. 5, No. 5, 851-868, 2020

https://doi.org/10.33889/IJMEMS.2020.5.5.066

\section{Methodology}

The present work can be considered an exploratory and descriptive study, based on a three-step methodology (Figure 1), including observation, categorization and association macro phases (Prasetyo and Arman, 2017).

The first step performed a bibliographic research to standardize information about the technologies, principles and attributes of Industry 4.0 and LM. The categorization elaborated the review structure, which analyzed each of the LM tools, as well as the technologies 4.0, for development of technological and industrial mappings. The association consisted in a relationship matrix between technologies 4.0 and LM tools, as well as six multi-level circular diagrams to illustrate the synergy points between these two concepts.

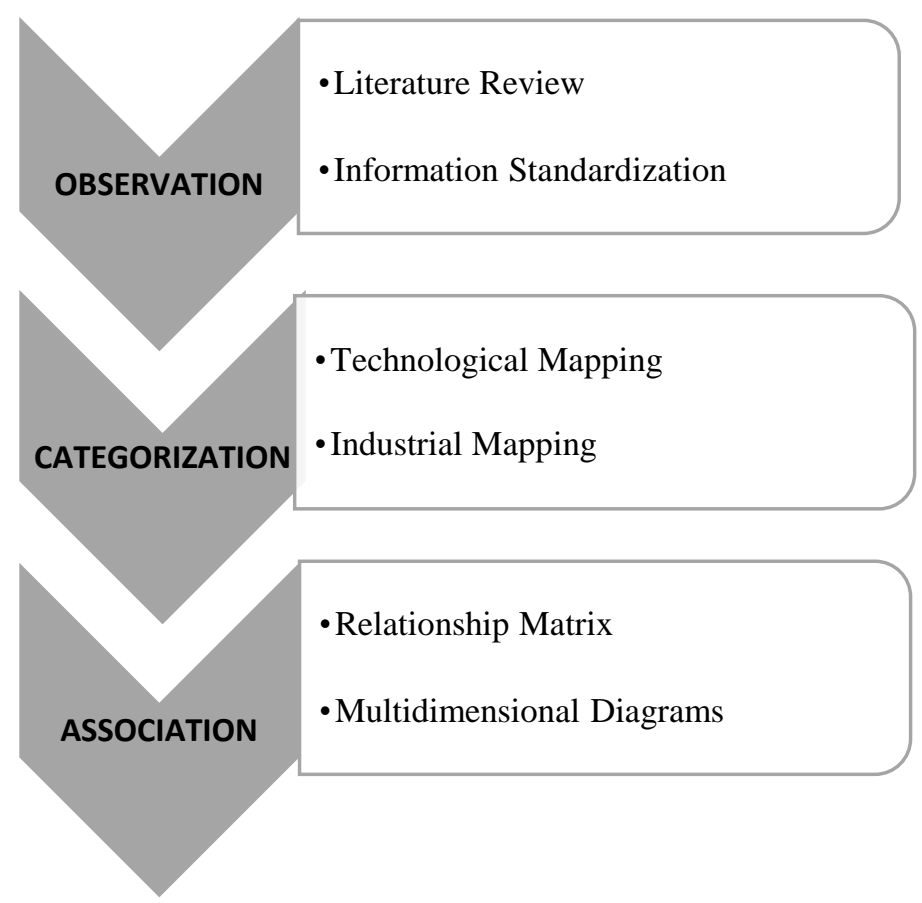

Figure 1. Research methodology stages applied in this study

In the first step, a literature review was performed to identify the principles, attributes and guiding concepts of LM and Industry 4.0. The databases Web of Science, ScienceDirect, Scopus and IEEE Xplore were used; main fields of research included Lean Manufacturing, Toyota Production System, Lean Thinking, Lean Methodologies and Tools, Industry 4.0, Cyberphysical System, Emerging Technologies, Attributes 4.0, and Intelligent Factories. Inclusion and exclusion criteria of articles, data definition to be selected from articles, analysis, discussion and results presentation were considered as steps of the literature review.

An industrial mapping was developed in the categorization step and LM was evaluated in relation to its implementation model, attributes, tools and practices applied in the production context. As the first topic addressed, the history of the LM concept was searched, focusing on its emergence 
and characteristics which constitute the TPS. Once the importance of the LM approach in production systems has been explained, the following LM-focused tools were studied and detailed. Each LM tool was described according to LM philosophy, considering JIT, Kanban, Poka-Yoke, VSM, Kaizen and TPM.

Also, the data standardization about Industry 4.0 was developed considering the current status of the Fourth Industrial Revolution, from the technological perspective. This paper developed an analysis of Industry 4.0 from the point of view of systems, processes and technology, in order to allow a micro view of this new approach and to glimpse how these elements are configured in the productive chain. Therefore, for Industry 4.0 technology mapping, the main technologies were identified, consisting of Big Data Analytics, AGVs, VS, Cybersecurity, The Cloud, AM and AR. The characterization of each technology was performed, considering the principles and characteristics of implementation.

Finally, in the association step, the relationship matrix was developed to evaluate the potential of integration between LM and Industry 4.0, covering the analysis of how the impacts of technologies 4.0 can influence the LM-focused tools. Synergy points indicated in the matrix was also represented by a multi-level circular diagrams, covering each LM tool, the adherent technologies 4.0 and, the attributes of this interaction (Figure 2), pointing out the main contributions of JIT 4.0, Kaizen 4.0, Kanban 4.0, Poka-Yoke 4.0, VSM 4.0, TPM 4.0.

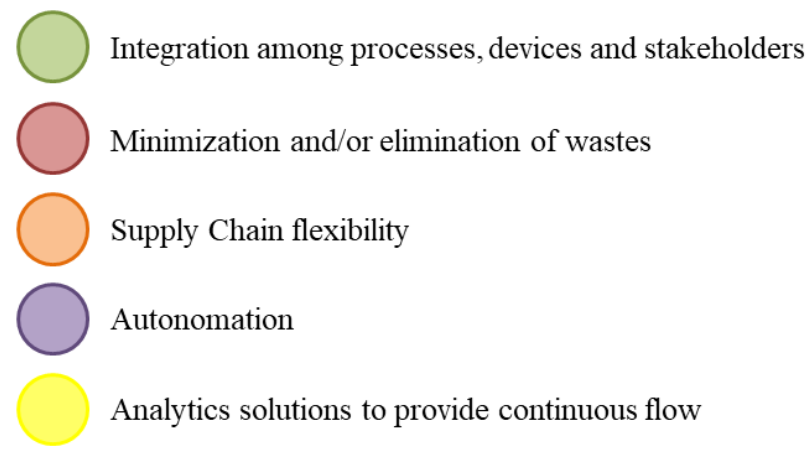

Figure 2. Attributes of LM and Industry 4.0 integration

Attributes of the Lean 4.0 was classified in five dimensions presented on Figure 2, consisting in (i) integration among processes, devices and stakeholders; (ii) minimization and/or elimination of wastes; (iii) supply chain flexibility; (iv) autonomation; (v) and analytics solutions to provide continuous flow. These categories represented the main attributes resulted from the integration between LM and Industry 4.0, considered, in this paper, the contributions of this relationship to organization environment.

\section{Results and Discussion}

According to Table 2, it is noteworthy that for each technology 4.0 addressed in this study, at least two relationships with LM tools were identified, resulting in 25 synergy points. Big Data Analytics (5), The Cloud (5), AGVs (4), VS (4) and AR (4) presented the highest number of relationships 
International Journal of Mathematical, Engineering and Management Sciences

Vol. 5, No. 5, 851-868, 2020

https://doi.org/10.33889/IJMEMS.2020.5.5.066

with lean philosophy. TPM was the tool that showed the greatest potential for convergence with digital technologies, totaling six points of interaction.

Each relationship between the two approaches was explained followed by its respective multi-level circular diagram. Therefore, LM tools, the adherent technologies 4.0 and, then, the attributes of this interaction resulted in a total of 68 points of contribution among the six diagrams, encompassing integration among processes, devices and stakeholders (16); minimization and/or elimination of wastes (16); supply chain flexibility (10); autonomation (16); and analytics solutions to provide continuous flow (10).

Table 2. Conceptual combination among LM tools and technologies 4.0

\begin{tabular}{|l|c|c|c|c|c|c|c|}
\cline { 2 - 8 } \multicolumn{1}{c|}{} & \multicolumn{7}{c|}{ TECHNOLOGIES 4.0 } \\
\hline LM TOOL & $\begin{array}{c}\text { Big Data } \\
\text { Analytics }\end{array}$ & AGVs & AM & The Cloud & Cybersecurity & VS & AR \\
\hline JIT & $\mathrm{X}$ & $\mathrm{X}$ & $\mathrm{X}$ & $\mathrm{X}$ & & & $\mathrm{X}$ \\
\hline Kanban & $\mathrm{X}$ & $\mathrm{X}$ & & & & $\mathrm{X}$ & \\
\hline Poka-Yoke & & $\mathrm{X}$ & & $\mathrm{X}$ & $\mathrm{X}$ & & $\mathrm{X}$ \\
\hline VSM & $\mathrm{X}$ & & & $\mathrm{X}$ & & $\mathrm{X}$ & \\
\hline Kaizen & $\mathrm{X}$ & & & $\mathrm{X}$ & & $\mathrm{X}$ & $\mathrm{X}$ \\
\hline TPM & $\mathrm{X}$ & $\mathrm{X}$ & $\mathrm{X}$ & $\mathrm{X}$ & & $\mathrm{X}$ & $\mathrm{X}$ \\
\hline
\end{tabular}

\subsection{Just-In-Time 4.0}

Considered one of the pillars of the TPS, JIT aims to produce the product in the right quantity, time, quality, location and manufacturing costs, without the need to develop a product inventory. However, in current logistics system, JIT objectives are not always fulfilled due to incomplete products status, incompatibility between required and transported products, and unexpected delays during transportation processes (Mayr et al., 2018; Sanders et al., 2016).

According to Figure 3, technologies 4.0 can contribute to more efficiently achieve the goals of this approach, including the application of The Cloud, Big Data Analytics, AGVs, AM and AR. The use of these technologies provides four attributes resulted from LM and Industry 4.0 relationship, principally the supply chain flexibility and integration among processes, devices and stakeholders. These tools, when put into practice in the production environment, provide a continuous, transparent, automated, and customer-driven product and information flow.

Receiving real-time supply chain data from several devices, sensors, computers and AGVs, The Cloud is able to share them with Big Data Analytics, which interprets and transforms these data in information for stakeholders to provide a better management. The Cloud is also connected with all employees from shop floor, sending data and interpreted information to their visual field through AR device, help them to solve issues and take better decisions quickly. Also, the exact personal customer request can be prepared by AM technologies, using less raw materials and process time, once this innovation produces only the quantity required with flexibility by adding material layers.

In fact, Sanders et al. (2016) state that The Cloud technology, when implemented in Internet of Things (IoT), has different integrated communication devices that manage information about transported products. Once each product has wireless tracking of its origin, destination, and current 
status, this technology 4.0 enables on-time delivery of items as well as optimizes transportation routes and logistics reliability, which adds value to customers.

As well as The Cloud, AGVs have made logistics automated, adjusting it in real-time according to production line needs. In accordance to Mayr et al. (2018), AGVs can carry objects within the material flow automatically, which minimizes human error as well as unnecessary travels.

Also included in IoT, Big Data Analysis techniques support JIT. Using this technology 4.0, it is possible to interpret detailed data of the production processes in real time, helping to identify trends and to derive rules for the system, which contributes to better performance of entire supply chain (Sanders et al., 2016).

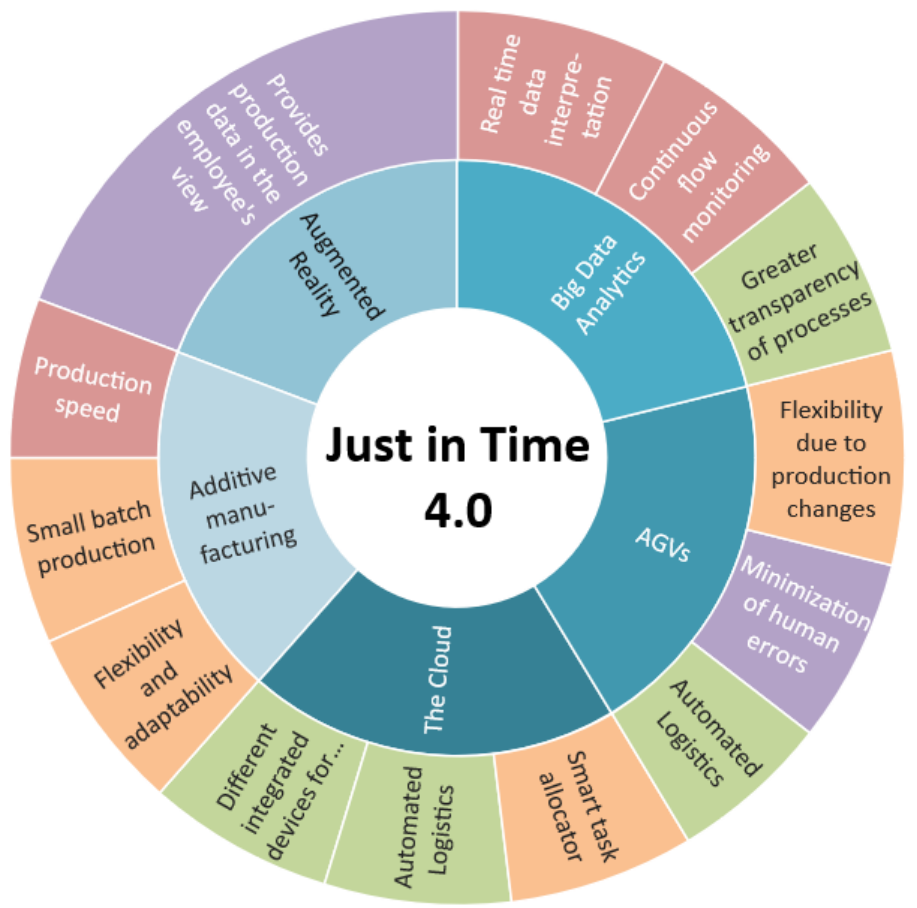

Figure 3. Just in Time 4.0: correlation between the JIT method with technologies 4.0

It is also emphasized that, according to Kolberg and Zuhlke (2015), AR displays cooperate to create a continuous production flow, which assists production line employees. Thus, cycle times information provided in the workers' visual field contributes for JIT system.

Frazier (2014) relates JIT with AM technologies, which favors small batch production. In this type of production, the high costs arising from the specific raw materials required are offset by the fixed costs reduction of conventional subtractive manufacturing methods. This advantage, combined with AM characteristics such as speed, versatility and adaptability, allow JIT production. 
International Journal of Mathematical, Engineering and Management Sciences

Vol. 5, No. 5, 851-868, 2020

https://doi.org/10.33889/IJMEMS.2020.5.5.066

\subsection{Kanban 4.0}

Kanban is a tool for implementing customer pull production and promotes a continuous material flow with waste-free processes, while maintaining a pre-defined inventory level to ensure uninterrupted material supply. It is noted that the inadequate monitoring of materials quantity supplied to production line, as well as changes in the production schedule, could severely alter this pull system (Mayr et al., 2018; Sanders et al., 2016).

In traditional LM flow, changes in production processes, regulatory stocks, or cycle times required complicated adjustments to Kanban cards. These variations limited the LM adequacy for individual and customized products or products with shorter life cycles (Kolberg and Zühlke, 2015).

However, in the context of Industry 4.0, new solutions are available to be incorporated into Kanban systems, such as Big Data Analytics, AGVs, and VS, which are synthesized in Figure 4. Four Lean 4.0 attributes are afforded, which two of them are highlighted with three designation points, being the integration among processes, devices and stakeholders, and the minimization and/or elimination of wastes. Applying these technologies, intermediate material stocks can be reduced to a minimum, as Big Data Analytics contributes to production flow real-time monitoring, which provides automated logistics with intelligent inventory control.

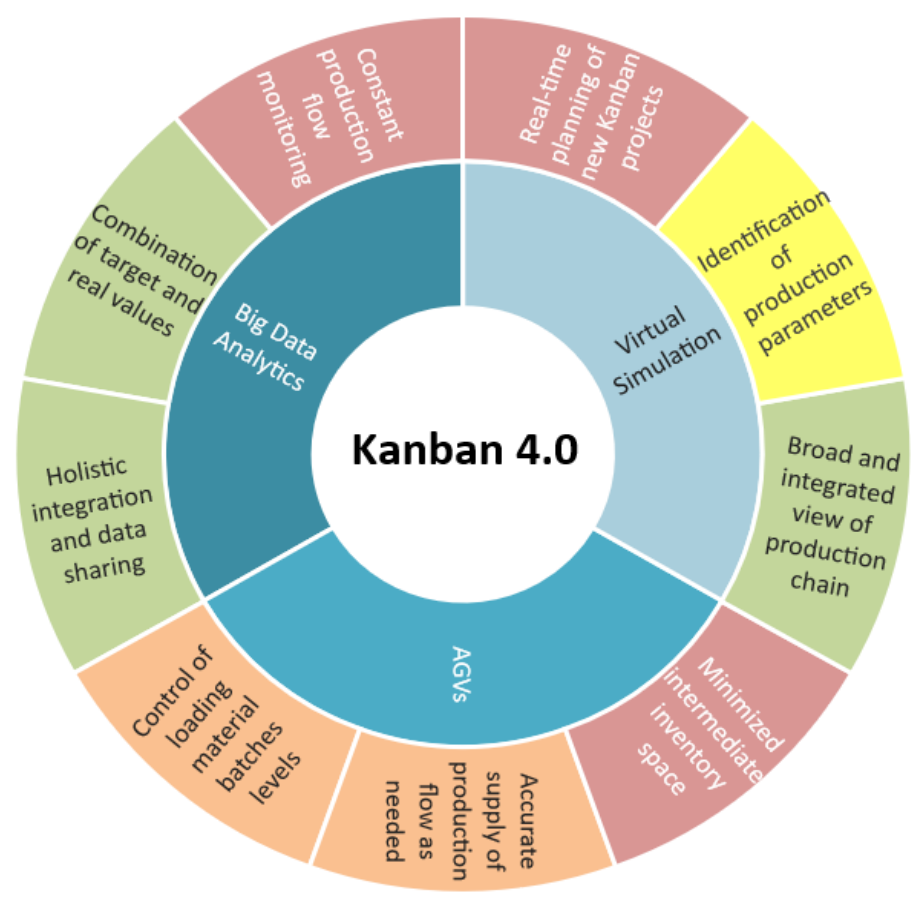

Figure 4. Kanban 4.0: correlation between the Kanban tool with technologies 4.0

The constant transformation of data into information from the entire production flow is essential to create new Kanban systems, designed through VS technologies. This technology 4.0 is able to present multiple perspectives of productive contexts, which anticipates solutions and predicts the production behavior to reduce bottlenecks. AGVs, in turn, replenish work stations according to real 
International Journal of Mathematical, Engineering and Management Sciences

Vol. 5, No. 5, 851-868, 2020

https://doi.org/10.33889/IJMEMS.2020.5.5.066

and exact needs of the production line, reducing inventories, lead times and unnecessary movements.

In fact, combining the Kanban with technologies, an e-Kanban system can be developed to replace conventional physical cards. This virtual Kanban is able to recognize empty box to trigger automatic replenishment, to control the level of material batches loading and to monitor the production schedule changes (Sanders et al., 2016).

Acting in conjunction with other technologies, Big Data Analytics constantly tracks workflow in progress, once it receives data from multiple factory sources. Then, this technology 4.0 increases the transparency of material and process movements, and enables the combination of target and actual values to remove unnecessary stock.

The AGVs are another innovation raised by Mayr et al. (2018), which further contribute to material reduction. These vehicles replenish production lines at the exact moment when more material is needed, reducing the need to fill multiple stock points with the same feature.

Using software of VS, new Kanban projects can be planned in real time, resulting in a broader and more integrated view of the production flow. Through simulations, optimal parameters for this LM tool can be automatically identified and updated, such as lot size, inventory, and delivery frequency (Kolberg and Zühlke, 2015).

\subsection{Poka-Yoke 4.0}

The Poka-Yoke mechanisms promote detection and elimination of abnormal conditions in production processes to prevent defective products creation. This LM tool generates forced sequences in the production lines and reviews the processes during their execution, stopping them in cases of errors and issues founded (Zhang, 2014).

According to Figure 5, AGVs, The Cloud, Cybersecurity and AR technologies 4.0 have relationships with this Lean tool. It's also noted that Poka-Yoke 4.0 presented all of the main attributes from LM and Industry 4.0 association, among which stands out the benefit of minimization and/or elimination of wastes, with four contribution points. Since the logic of Poka-Yoke is to prevent errors in production systems, AGVs are able to quickly adapt to possible flow failures and inform The Cloud about the problems encountered for later analysis and resolution. AR, in turn, works together with employees, helping them in their manual tasks to avoid possible slips, as well as presenting instructions and virtual elements in their displays that facilitate the understanding and performance of activities.

In order to maintain a flawless environment, Poka-Yoke directly contributes to improving the security of productive operations, working side by side with cybersecurity systems.

Mayr et. al. (2018) identified the benefits of AGVs in production chains. These devices are capable to act together with the employees and to adjust automatically in various line functions considering possible irregularities, ensuring the total quality of the manufactured product.

Mrugalska and Wyrwicka (2017) also demonstrated that using actuators, sensors and wireless video, the flow robots and machines collect data from the production line. These data are analyzed 
and pursued in The Cloud to provide a better operational intelligence, as well as to avoid possible production errors, which relates with the central idea of Poka-Yoke tool.

Offering significant advantages such as speed, reliability, and reduced failure rate, AR technology supports the worker in real time during manual operations, assisting to reduce human errors. Presenting intuitive information in its displays combined with collaborator intelligence, AR can enable Poka-Yokes digital systems for work-intensive functions. These systems provide greater efficiency in completing manual tasks, which minimizes the occurrence of defects, rework and redundant inspection, while improves the work quality (Romero et al., 2016).

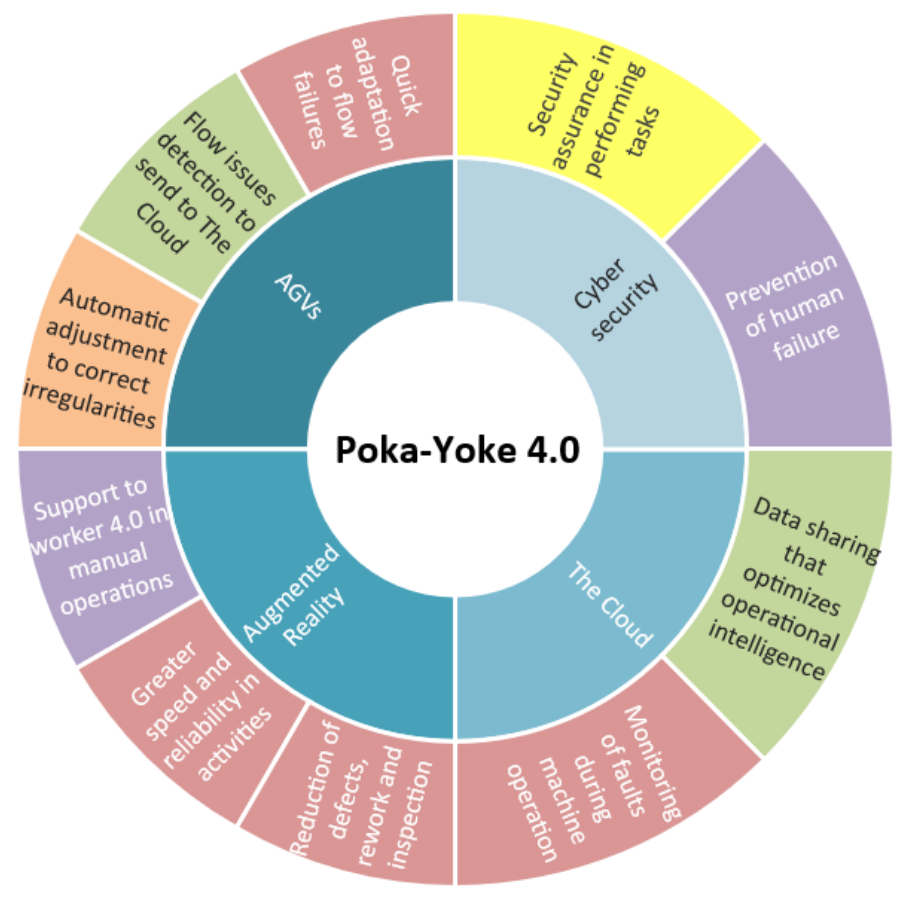

Figure 5. Poka-Yoke 4.0: correlation between the Poka-Yoke tool with technologies 4.0

Considering that this LM tool prevents, corrects, and warns the operator errors as they occur, PokaYoke devices are especially useful in operations that require the use of hardware. In this context, Harris and Simpson (2016) state that smart implementation of human factor theories and techniques during the hardware design development can prevent failures and ensure greater security in performing tasks.

\subsection{Value Stream Mapping 4.0}

Comprising all activities that constitute the production chain, VSM aims to identify non-valueadded processes that are considered waste. Once found, improvement solutions are developed to correct these bottlenecks to optimize the production flow (Ellingsen, 2017).

Smart factories will provide a fully integrated manufacturing environment where data can be transmitted in real time. The use of emergent technologies contributes with four attributes of Lean 
4.0 (Figure 5). Equally to Poka-Yoke 4.0, the minimization and/or elimination of wastes is the benefit with the higher number of advantages, also totalizing four points. Featuring Big Data Analytics and The Cloud, VSM will continually receive new data and information from the entire supply chain, streamlining both flow management and bottlenecks identification. This smart management process is also optimized by VS techniques, allowing multiple mapping possibilities to be studied and interpreted by managers before they are put into practice, which contributes to decision making.

Through sensors, actuators and human-computer interaction devices located in robots, intelligent products and machines, equipment performance data and the objects location will be automatically collected, allowing the VSM 4.0 (Figure 6) constant update.

Also, simultaneous update facilitates the Big Data Analytics data consolidation, which enables factbased decisions making. Besides, through The Cloud, the physical resources of the production floor are linked with supervisory and control terminals. This environment provides information remotely retrievable for stakeholders, who access interpreted data as well as the current map with future strategic planning activities and processes control through tablets, smartphones and displays (Mayr et al., 2018).

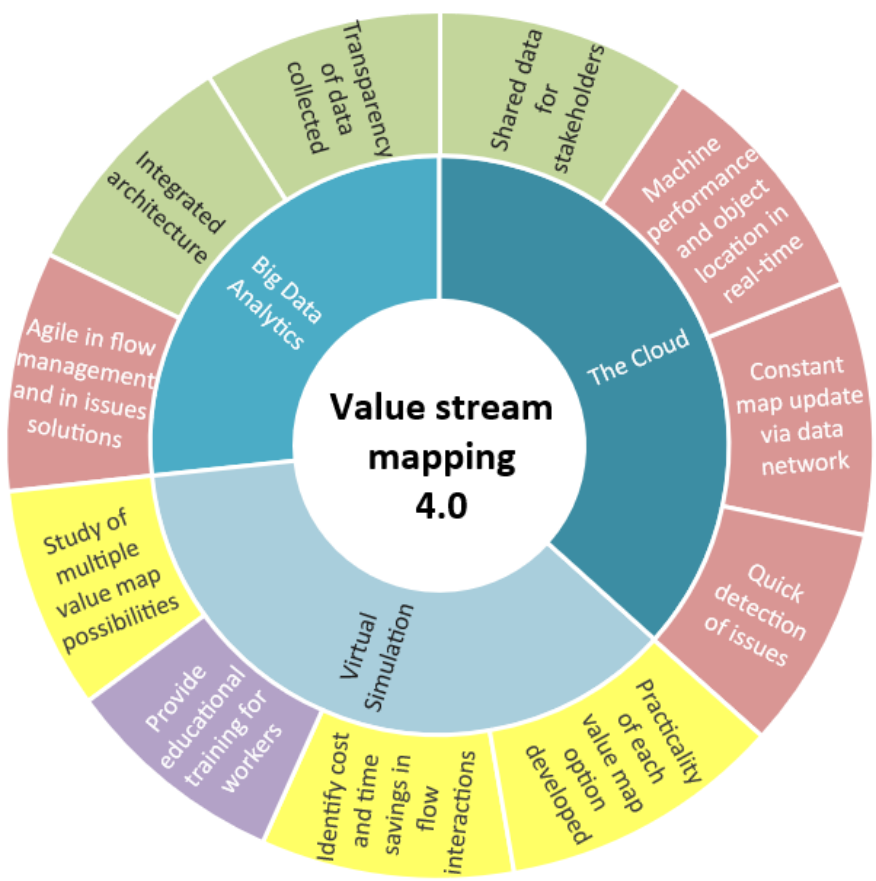

Figure 6. Value Stream Mapping 4.0: correlation between the VSM tool with technologies 4.0

The association between VS technology with this LM tool also benefits the production, since this technology 4.0 allows a preview map before been introduced in real production. This allows teams to investigate, in multiple scenarios, the possible interactions between the flow elements and their respective cost and time savings. With several VSM simulations, managers can provide better 
training for workers, as well as study the practicality of each map options developed (Esfandyari et al., 2011).

A comparison with the classic VSM points out that, in the traditional method, information flows to machines, workers or factory floor management were not mapped and analyzed. However, VSM 4.0 solves this gap and brings a new direction of information in value flows, becoming a dynamic tool (Mayr et al., 2018; Wagner et al., 2017).

\subsection{Kaizen 4.0}

Embracing all employees of an organization, Kaizen aims to promote continuous improvement, through multifunctional teams training and productive activities planning, with the objective of identifying gaps and developing new methods to solve possible issues (Maarof and Mahmud, 2016).

To facilitate the Kaizen performance, technologies 4.0 act to contribute to continuous improvement, such as Big Data and Analytics, The Cloud, VS and AR, which are showed in Figure 7. Applying these technologies 4.0, four LM and Industry 4.0 collaboration attributes are identified, which stands out the benefit of Autonomation, with five points accounted.

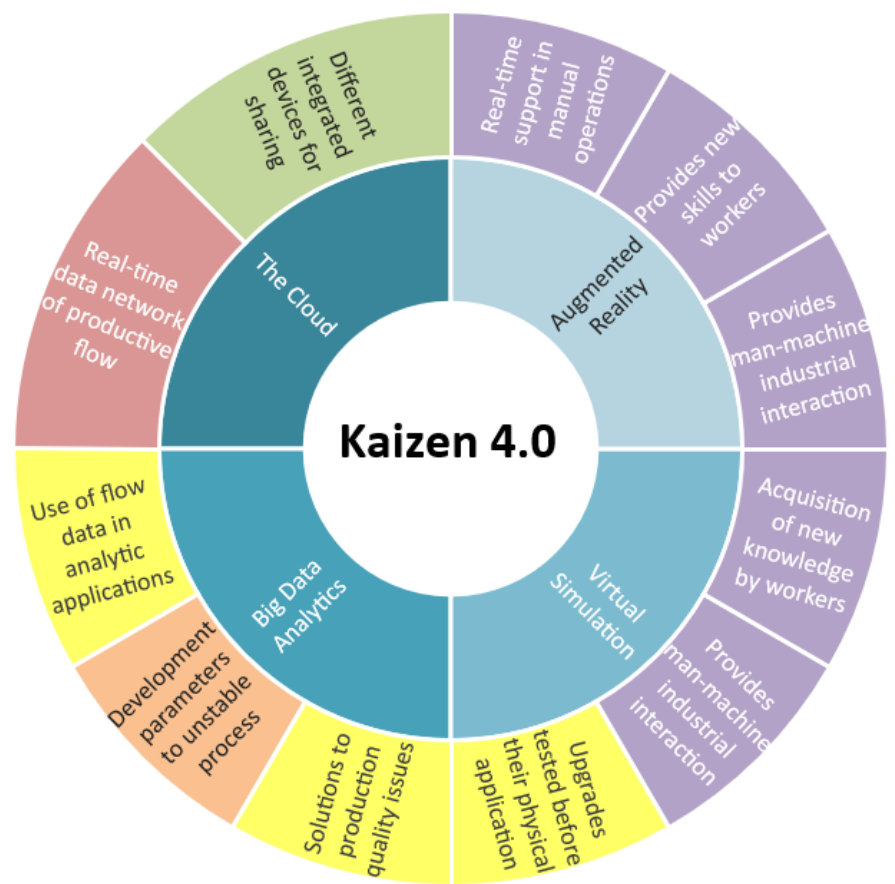

Figure 7. Kaizen 4.0: correlation between the Kaizen tool with technologies 4.0

Data from production processes and smart device, as well as from stakeholders, are collected and shared in a cloud computing environment with speed and variability. These data are later analyzed by Big Data Analytics, contributing to achieve results and solutions that provide continuous flow and, consequently, corroborate the Kaizen philosophy. 
The association of VS with AR, in turn, narrows the human-machine relationship by empowering employees with new knowledge about production processes. Thus, employees become more critical and able to find possible issues to be resolved in production line.

In fact, Wagner et al. (2017) explained that products, resources, and machines become smart artifacts and connected to the global internet using technologies such as hardware-based sensors, actuators that interact with the physical world, and middleware with The Cloud services. Thus, the data from these items are collected and stored, making them available for use in analytical applications. The interpretation of these data enables the development of unstable process parameters and avoids problems in production quality, contributing to continuous improvement.

The VS encompasses industrial applications such as assembling, simulating, evaluating and visualizing product designs and training employees. These activities variability stands out as a technology with the potential to better significantly the conventional continuous improvement processes. Unwanted interruptions in the production line can be reduced and the improvements ideas can be tested before their actual physical application. This innovation 4.0, coupled with AR, enables man-machine industrial interaction through information sharing, which reinforces employees' acquisition of new knowledge and skills (Aurich et al., 2009; Wagner et al., 2017).

\subsection{Total Productive Maintenance 4.0}

Zero defect tolerance and productivity optimization are two of the main prerequisites in the manufacturing industries. In this scope, maintenance activities are considered essential to ensure the proper functioning of machines and equipment and, consequently, to the entire production line. The importance of these activities stands out on smart factories, once technical complexity and intelligent artifacts quantity are higher. In this scenario 4.0, unplanned deployments can result in high costs to the organization. Even with preventive and periodic maintenance schedules, machine failures are not completely under control, and if a problem occurs on production flow, it may be spent a considerable time until find the root cause and solving it (Mayr et al., 2018; Sanders et al., 2016).

According to Figure 8, Big Data Analytics, AGVs, The Cloud, VS, AR, and AM are technologies from Industry 4.0 that contribute to this LM principle. Working together, these technologies contribute, for example, to predicting new equipment failures, quickly detecting errors, and sending instructions to maintenance teams. Just like Poka-Yoke 4.0, TPM 4.0 has all LM and Industry 4.0 collaboration attributes, and the benefit Autonomation highlights with six indication points.

Once The Cloud shares data about the processes and devices status in real time, the machines are frequently monitored. In addition, The Cloud sends data to Big Data Analytics to analyze and manage maintenance team activities from current and future line needs. The combination of VS and $\mathrm{AR}$ instructs these employees to perform maintenance tasks efficiently and at the right frequency.

Mayr et al. (2018) and Sanders et al. (2016) reinforce that smart products and equipment are capable to monitor load, wear and defects indexes during machine operation, using sensors, actuators and other devices. Machines are interconnected with information and communication systems in The Cloud; when one of machines fails, it sends notifications to the shop floor and to maintenance staff. Early detection, isolation and fault identification result in less lead time and in consequential damage prevention. 


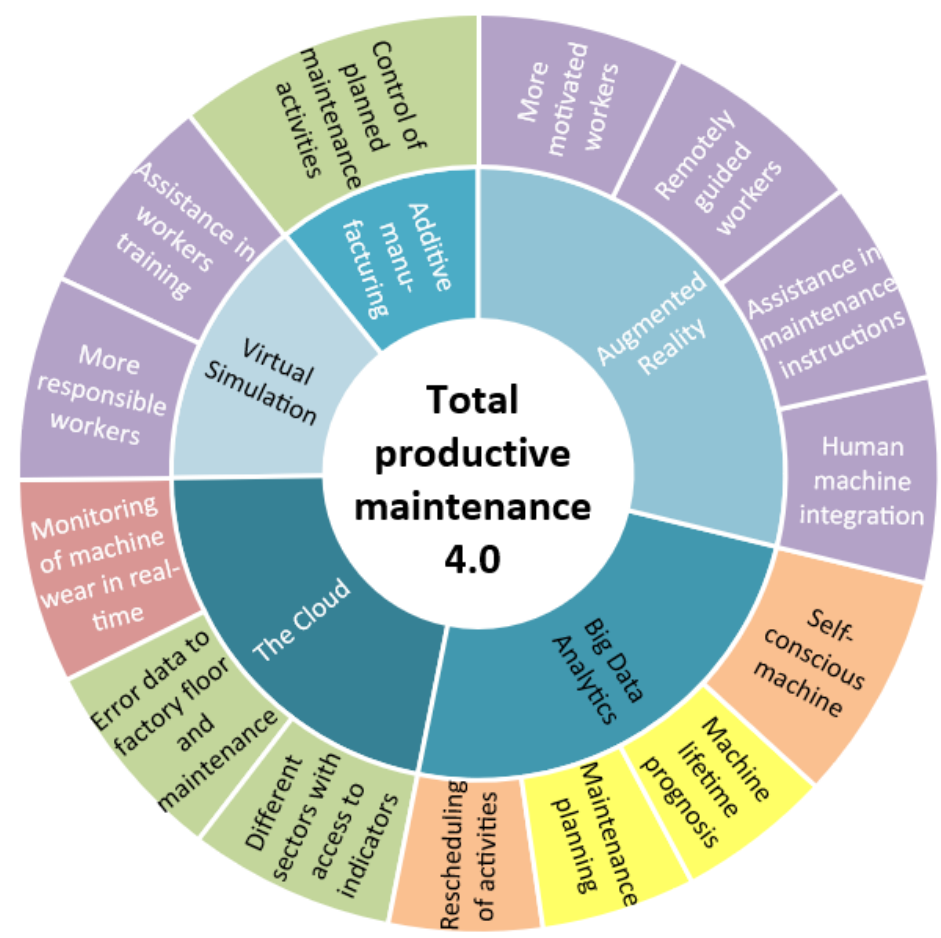

Figure 8. Total Productive Maintenance 4.0: correlation between the TPM tool with technologies 4.0

The same authors also argue about maintenance planning, a practice based on machine failures history, which uses predictive analysis to correlate conditions flow parameters with equipment error probabilities. Based on data from Big Data, this analysis uses complex algorithms to predict defects, which may increase the accuracy of life expectancy of these instruments.

The combination of reality and virtual simulation instruments with AR instruments is also identified by Mayr et. al. (2018). Since maintenance typically involves non-recurring and context-sensitive activities, the interaction of factory floor operators with maintenance specialists becomes crucial.

AM devices are based on digital design models to produce custom components. This type of manufacturing can extend control and services with focus on product to tasks and operations beyond manufacturing, such as assembly, delivery, product improvement and maintenance, especially planned maintenance activities (Mayr et al., 2018; Singh et al., 2013).

\section{Conclusion}

Out of a total of 42 relationship possibilities, it was identified 25 synergy points from an holistic integration perspective, which means that LM and Industry 4.0 can work together and collaborate mutually. Even though they are two fundamentally different approaches, the objective of constantly adding value to production systems is equivalent in both ideologies, which results in Lean 4.0 combination concept. 
According to the synergy points, it was concluded that both concepts of LM and Industry 4.0 can coexist and support each other. Five main Lean 4.0 attributes resulted in a total of 68 contribution points among the six relationship diagrams. The dimensions of integration among processes, devices and stakeholders; minimization and/or elimination of wastes; and autonomation presented the higher indication points quantity, resulting 16 each.

Therefore, being a term to represent the association between these two approaches, Lean 4.0 points to low complexity automation solutions that fit into LM environment, aiming to get a greater change capability and lower information flows to meet future market demands, which strengthen the competitive margins of manufacturing companies.

With the objective of eliminate waste in production processes, LM speeds up production flow, facilitating digitization of manufacturing steps, and emphasizing visual and transparent control, making it easier to identify failures. These LM principles contribute significantly to the development of Industry 4.0, as technologies 4.0 will be underpinned by LM practices to maximize production performance. Smart factories, in turn, promote value chain digitalization and real-time data of inventory levels, equipment status and product location.

Therefore, Industry 4.0 technologies increase the maturity of LM once that for JIT success, the information generated must be accurate, up-to-date and shared every moment. With focus on customer pull production, Kanban devices are potentiated by emerging tools, englobing the entire horizontal and vertical supply chain, and not just internal production and logistics processes. Smart Poka-Yoke devices, in turn, work with real-time data from production flow, being more effective in reducing waste, as well as preventing the issues spread to next workstations. The interconnection between machines, processes and employees provided by technologies 4.0 makes VSM tool able to monitor value flows in real time for the quick resolution of possible wastes, including lead time and machine configuration costs. The Industry 4.0 benefits regarding module integration, data sharing and analyses, human-machine association and employee training, support the Kaizen philosophy of continuous improvement, as well as maintenance planning and activities.

\section{Conflict of Interest}

The authors declare no conflict of interest for this publication.

\section{Acknowledgements}

To Brazilian National Council for Scientific and Technological Development (CNPq) for providing financial support for this research.

\section{References}

Alkan, B., Vera, D.A., Ahmad, M., Ahmad, B., \& Harrison, R. (2018). Complexity in manufacturing systems and its measures: a literature review. European Journal of Industrial Engineering, 12(1), 116-150.

Aurich, J.C., Ostermayer, D., \& Wagenknecht, C.H. (2009). Improvement of manufacturing processes with virtual reality-based CIP workshops. International Journal of Production Research, 47(19), 5297-5309.

Bahrin, M.A.K., Othman, M.F., Azli, N.H.N., \& Talib, M.F. (2016). Industry 4.0: a review on industrial automation and robotic. Jurnal Teknologi, 78(6-13), 137-143. 
International Journal of Mathematical, Engineering and Management Sciences

Vol. 5, No. 5, 851-868, 2020

https://doi.org/10.33889/IJMEMS.2020.5.5.066

Behrouzi, F., \& Wong, K.Y. (2011). Lean performance evaluation of manufacturing systems: a dynamic and innovative approach. Procedia Computer Science, 3, 388-395.

Ben-Daya, M., Hassini, E., \& Bahroun, Z. (2019). Internet of things and supply chain management: a literature review. International Journal of Production Research, 57(15-16), 4719-4742.

Chang, A.Y., \& Cheng, Y.T. (2019). Analysis model of the sustainability development of manufacturing small and medium-sized enterprises in Taiwan. Journal of Cleaner Production, 207(10), 458-473.

Čiarnienè, R., \& Vienažindienè, M. (2012). Lean manufacturing: theory and practice. Economics \& Management, 17(2), 726-732.

Dombrowski, U., Richter, T., \& Krenkel, P. (2017). Interdependencies of industrie 4.0 \& lean production systems: a use cases analysis. Procedia Manufacturing, 11(June), 1061-1068.

Eliasen, B., Tan, K., Ohler, L.P., Lindeburg, E., \& Perälä-Heape, M. (2018). Digital health revolution: person centric data management models and opportunities in the healthcare sector, the nordic way. University of Oulu, Oulu. Finland.

Ellingsen, O. (2017). Commercialization within advanced manufacturing: value stream mapping as a tool for efficient learning. Procedia CIRP, 60, 374-379.

Esfandyari, A., Osman, M.R., Ismail, N., \& Tahriri, F. (2011). Application of value stream mapping using simulation to decrease production lead time: a Malaysian manufacturing case. International Journal of Industrial and Systems Engineering, 8(2), 230-250.

Frazier, W.E. (2014). Metal additive manufacturing: a review. Journal of Materials Engineering and Performance, 23, 1917-1928.

Harris, S., \& Simpson, B. (2016). Human error and the international space station: challenges and triumphs in science operations. In: SpaceOps 2016 Conference, Daejeon, Korea (pp. 1-13).

Javaid, M., \& Haleem, A. (2019). Industry 4.0 applications in medical field: a brief review. Current Medicine Research and Practice, 9(3), 102-109.

Knechtges, P., \& Decker, M.C. (2014). Application of kaizen methodology to foster departmental engagement in quality improvement. Journal of the American College of Radiology, 11(12), 1126-1130.

Kolberg, D., \& Zühlke, D. (2015). Lean automation enabled by industry 4.0 technologies. IFACPapersOnLine, 48(3), 1870-1875.

Ma, J., Wang, Q., \& Zhao, Z. (2017). SLAE-CPS: Smart lean automation engine enabled by cyber-physical systems technologies. Sensors (Switzerland), 17(7), 1500.

Maarof, M.G., \& Mahmud, F. (2016). A review of contributing factors and challenges in implementing kaizen in small and medium enterprises. Procedia Economics and Finance, 35(October 2015), 522-531.

Mayr, A., Weigelt, M., Kühl, A., Grimm, S., Erll, A., Potzel, M., \& Franke, J. (2018). Lean 4.0-a conceptual conjunction of lean management and Industry 4.0. Procedia CIRP, 72(1), 622-628.

Mrugalska, B., \& Wyrwicka, M.K. (2017). Towards lean production in industry 4.0. Procedia Engineering, $182,466-473$.

Pagliosa, M., Tortorella, G., \& Ferreira, J.C.E. (2019). Industry 4.0 and lean manufacturing: a systematic literature review and future research directions. Journal of Manufacturing Technology Management, Vol. ahead-of-print No. ahead-of-print. https://doi.org/10.1108/JMTM-12-2018-0446.

Pereira, A.C., Dinis-Carvalho, J., Alves, A.C., \& Arezes, M.P. (2019). How industry 4.0 can enhance lean practices. FME Transactions, 47(4), 810-822. 
International Journal of Mathematical, Engineering and Management Sciences

Vol. 5, No. 5, 851-868, 2020

https://doi.org/10.33889/IJMEMS.2020.5.5.066

Prasetyo, Y.A., \& Arman, A.A. (2017, October). Group management system design for supporting society 5.0 in smart society platform. In 2017 International Conference on Information Technology Systems and Innovation (ICITSI) (pp. 398-404). IEEE. Bandung, Indonesia.

Romero, D., Stahre, J., Wuest, T., Noran, O., Bernus, P., Fast-Berglund, ̊., \& Gorecky, D. (2016, October). Towards an operator 4.0 typology: a human-centric perspective on the fourth industrial revolution technologies. In Proceedings of the International Conference on Computers and Industrial Engineering (CIE46), pp. 29-31. Tianjin, China .

Rüßmann, M., Lorenz, M., Gerbert, P., Waldner, M., Justus, J., Engel, P., \& Harnisch, M. (2015). Industry 4.0: the future of productivity and growth in manufacturing industries. Boston Consulting Group, 9(1), 54-89.

Sanders, A., Elangeswaran, C., \& Wulfsberg, J.P. (2016). Industry 4.0 implies lean manufacturing: research activities in industry 4.0 function as enablers for lean manufacturing. Journal of Industrial Engineering and Management, 9(3), 811-833.

Schmidt, R., Möhring, M., Härting, R.C., Reichstein, C., Neumaier, P., \& Jozinović, P. (2015) Industry 4.0 - potentials for creating smart products: empirical research results. In: Abramowicz, W. (ed) Business Information Systems. BIS 2015. Lecture Notes in Business Information Processing, vol 208. Springer, Cham.

Singh, R., Gohil, A.M., Shah, D.B., \& Desai, S. (2013). Total productive maintenance (TPM) implementation in a machine shop: a case study. Procedia Engineering, 51 (December 2012), 592-599.

Tayaksi, C., Sagnak, M., \& Kazancoglu, Y. (2020). A new holistic conceptual framework for leanness assessment. International Journal of Mathematical, Engineering and Management Sciences, 5(4), 567590.

Ustundag, A., \& Cevikcan, E. (2018). Industry 4.0: managing the digital transformation. Springer, Cham. Print ISBN 978-3-319-57869-9.

Vaidya, S., Ambad, P., \& Bhosle, S. (2018). Industry 4.0 - a glimpse. Procedia Manufacturing, 20, 233-238.

Wagner, T., Herrmann, C., \& Thiede, S. (2017). Industry 4.0 impacts on lean production systems. Procedia CIRP, 63, 125-131.

Womack, J.P., Jones, D.T., \& Roos, D. (1990). The machine that changed the world. Rawson Associates, New York.

Zhang, A. (2014). Quality improvement through Poka-Yoke: from engineering design to information system design. International Journal of Six Sigma and Competitive Advantage, 8(2), 147-159. 